\title{
The Impact of a Structured Virtual Reality Simulation Training Curriculum for Novice Endoscopists
}

\author{
Sofia Silva Mendes a, b, c Miguel Areiad,f Mário Dinis Ribeiro e,f Carla Rolanda a,b, c

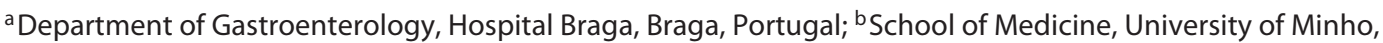 \\ Braga, Portugal; ' Life and Health Sciences Research Institute/3B's e PT Government Associate Laboratory, Braga/ \\ Guimarães, Portugal; ${ }^{d}$ Department of Gastroenterology, Portuguese Oncology Institute of Coimbra, Coimbra, Portugal; \\ e Department of Gastroenterology, Portuguese Oncology Institute of Porto, Porto, Portugal; ${ }^{\mathrm{f} C I D E S / C I N T E S I S, ~ P o r t o ~}$ \\ Faculty of Medicine, Porto, Portugal
}

Keywords

Training · Virtual simulator · Endoscopy $\cdot$ Education · Clinical competency

\section{Abstract}

Background: Current evidence supports the use of virtual reality (VR) simulation-based training for novice endoscopists. However, there is still a need for a standardized induction programme which ensures sufficient preparation, with knowledge and basic skills, before their approach to patientbased training. We designed a structured progressive programme in upper endoscopy and colonoscopy and aimed to determine its impact on cognitive and technical performance. Methods: Prospective, multicentre study, focused on "Endoscopy I, 2018," a course with a theoretical and a hands-on module (20 h) in the GI Mentor II ${ }^{\circledR}$. Gastroenterology residents of the 1st year were enrolled. A pre-test and test were applied to evaluate the cognitive component, and a pre-training and post-training esophagogastroduodenoscopy (EGD) and colonoscopy VR cases were used to evaluate the technical component. The hands-on training included psychomotor exercises (Navigation I, Endobubble I), 4 EGD, and 4 colonoscopy VR cases. The metrics applied for technical skills evaluation were time to reach the second portion of duodenum (D2)/cecum (seconds), efficiency of screening (\%), and time the patient was in pain (\%). Results: Twentythree participants were included, majority female (67\%), 26 \pm 0.7 years old. Comparing the pre-test versus test, the cognitive score significantly improved (11/15 vs. $14 / 15 ; p<$ $0.001)$. Considering the technical assessment after training: in $E G D$, the time to D2 was significantly lower (193 vs. 63 s; $p$ $<0.001)$, and the efficiency of screening significantly better (64 vs. $91 \% ; p<0.001$ ); in colonoscopy, the time to reach the cecum was significantly lower (599 vs. $294 s ; p=0.001$ ), the time the patient was in pain was significantly lower (27 vs. $10 \% ; p=0.005)$, and the efficiency of screening had a tendency towards improvement ( 50 vs. $68 \% ; p=0.062$ ). Conclusion: The proposed training curriculum in basic endoscopy for novices is aligned with international recommendations and demonstrated a significant impact on cognitive and technical skills learning achievements.

(c) 2021 Sociedade Portuguesa de Gastrenterologia Published by S. Karger AG, Basel karger@karger.com www.karger.com/pjg

Karger $\stackrel{\text { ' }}{5}$

GOPEN ACCESS (c) 2021 Sociedade Portuguesa de Gastrenterologia Published by S. Karger AG, Basel

This is an Open Access article licensed under the Creative Commons Attribution-NonCommercial-4.0 International License (CC BY-NC) (http://www.karger.com/Services/OpenAccessLicense), applicable to the online version of the article only. Usage and distribution for commercial purposes requires written permission.
Correspondence to:

Sofia da Silva Mendes, sofia.s.mendes@hb.min-saude.pt 
Impacto de um programa de treino estruturado com endoscopia de simulação para iniciados

\section{Palavras Chave}

Treino · Simulador virtual · Endoscopia · Educação · Competência clínica

\section{Resumo}

Introdução: A evidência científica suporta o uso de simuladores de realidade virtual na fase inicial da formação. Contudo, persiste a necessidade de um programa padronizado, que garanta uma preparação adequada dos formandos, com conhecimento e competências básicas, antes de transitarem para o treino em pacientes. Desenhámos um programa de treino estruturado e progressivo em endoscopia digestiva alta (EDA) e colonoscopia, pretendendo este estudo avaliar o seu impacto no desempenho cognitivo e técnico. Métodos: Estudo prospetivo e multicêntrico, focado no programa de treino "Endoscopia I, 2018." Este curso incluiu um módulo teórico e um módulo prático (20 h) no simulador GI Mentor II ${ }^{\circledR}$. Foram recrutados internos de Gastrenterologia do $1^{\circ}$ ano. Realizou-se um pré-teste e um teste para avaliar o componente cognitivo e foram usados casos virtuais selecionados, de EDA e colonoscopia, para avaliar o componente técnico pré e pós-treino. A prática incluiu exercícios psicomotores (Navigation I, Endobubble I), 4 casos virtuais de EDA e 4 de colonoscopia. As métricas aplicadas na avaliação foram o tempo até à segunda porção duodenal (D2)/cego (segundos), a eficiência da inspeção (\%) e o tempo que o paciente teve dor (\%). Resultados: Vinte e três participantes incluídos, a maioria do género feminino (67\%), com idade média de $26 \pm 0.7$ anos. Comparando o pré-teste versus (vs.) teste, o resultado da avaliação cognitiva melhorou ( $11 / 15$ vs. $14 / 15 ; p<0.001)$. Relativamente à avaliação técnica após o treino: na EDA, o tempo para alcançar D2 foi significativamente menor (193 vs. $63 s ; p<0.001$ ) e a eficiência da inspeção foi significativamente melhor (64 vs. $91 \%$; $p<001$ ); na colonoscopia, o tempo até ao cego foi significativamente menor (599 vs. $294 \mathrm{~s} ; p=0.001$ ), o tempo em que o paciente teve dor foi significativamente menor ( 27 vs. $10 \% ; p=0.005$ ) e a eficiência da inspeção revelou uma tendência de melhoria (50 vs. $68 \% ; p=0.062$ ). Conclusão: $O$ presente programa de treino em endoscopia básica para iniciados está alinhado com as recomendações internacionais e demonstrou um impacto significativo na aquisição de capacidades cognitivas e técnicas.

C 2021 Sociedade Portuguesa de Gastrenterologia Publicado por S. Karger AG, Basel

\section{Introduction}

The traditional master apprentice model in endoscopic training demands a difficult balance between the patient's interests and the trainee's needs [1]. Hence its exclusive use is nowadays less accepted, and simulation emerged as an educational solution, allowing repetitive instruction in a non-patient environment, which is less stressful and risk-free.

In the early training, mechanical models and virtual reality (VR) simulators are the most frequently used [1$3]$. VR endoscopy simulators are integrated systems with mechanical parts and software. The included haptic and visual interfaces allow the trainee to practice cognitive and technical skills under varying conditions. The training experience can be standardized, and the exercises repeated until fully mastered. Performance is expressed in parameters measured and recorded by the system, which can be useful in customization of benchmarks for competency assessment [2-4].

Some of the commercially available VR equipment has already been validated and proved to have discriminative abilities for dexterity and competence in flexible endoscopy $[5,6]$. Moreover, some studies provided high-quality evidence for the positive effect of simulator training in novices, and the abilities acquired seem to translate into useable skills for patient-based colonoscopy and upper endoscopy [7-10]. This approach improves the novices' technical skills and accelerates the learning curve, while minimizing patients' risk and discomfort. Nevertheless, the simulator-based training is complementary and does not replace the patient-based training $[11,12]$. Moreover, the described benefit ceases when a minimum duration/ volume of training, or certain goals, are achieved $[9,10$, 13].

There is now enough evidence supporting basic training (upper endoscopy and colonoscopy) to start in a validated VR simulator (e.g., Simbionix GI Mentor $\mathrm{II}^{\circledR}$ ). An increasing number of medical centres worldwide have already incorporated it; however, there is no single optimal or recommended method for its integration $[14,15]$.

When considering the application of this educational tool, a diversity of factors must be considered, for instance, sessions' duration, periodicity, selected exercises, and senior endoscopist support, etc. All seem to influence the success of training and the outcomes $[2,16]$. On the subject of the selection of exercises, we previously conducted a pilot study and concluded that the psychomotor training (assumed in 2 validated exercises (Endobubble I and Navigation I) had a significant impact on homoge-
Silva Mendes/Areia/Dinis Ribeiro/ Rolanda 


$\begin{array}{ll}\text { Endoscopy } & \text { I } \text { Theoretical module } \\ \text { 08:45-09:00 } & \text { Welcome and introduction to objectives } \\ \text { 09:00-09:20 } & \text { Pre-test } \\ \text { 09:20-10:00 } & \text { Gl endoscopes (anatomy and types) } \\ \text { 10:00-10:40 } & \text { Basic accessories of endoscopy } \\ \text { 10:40-11:00 } & \text { Coffee break } \\ \text { 11:00-11:30 } & \text { Endoscopes reprocessing } \\ \text { 11:30-12:00 } & \text { Indications and contraindications for EGD and } \\ & \text { colonoscopy } \\ \text { 12:00-12:20 } & \text { EGD and colonoscopy technical approach } \\ \text { 12:20-12:40 } & \text { Test } \\ \text { 13:00 } & \text { Lunch } \\ \text { 14:15-18:00 } & \text { First contact with GI Mentor II }{ }^{\circledR}\end{array}$

Fig. 1. Structure of the "Endoscopy I" training programme - theoretical module.

neous acquisition and assimilation of colonoscopy skills, and that it should be considered in the training programmes for novices (unpublished).

Another important aspect is the programme: a structured and progressive simulation training (interactive theoretical sessions, simulation hands-on with trainer feedback), when compared with self-administered training, brings significant positive impact of the performance in patients [17], which is also more durable [18].

Based on these considerations, the Education Committee of the Portuguese Society of Digestive Endoscopy (SPED) designed a structured and innovative training programme, in endoscopy, for novice residents. The aim of this study was to evaluate its impact on performance and acquisition of cognitive and technical skills.

\section{Methods}

This was a prospective, observational, multicentre study, conducted by the Education Committee of SPED, to evaluate the impact of the "Endoscopy I, 2018." This course included a theoretical module held in May 2018, and a hands-on module on the GI Mentor II (Simbionix, Ltd., Israel) VR simulator for flexible endoscopy, and took place in September, October, and November 2018.

\section{Participants}

Portuguese gastroenterology residents of the first year, without any previous endoscopy experience, were invited to participate in the context of "Endoscopy I, 2018," a structured course provided by SPED to residents before they start endoscopy on patients. Sample size was dependent on the number of Portuguese new residents of gastroenterology in that year (2018). The research protocol was approved by the University of Minho (UM) Ethics Subcommission of Life and Health Sciences, and all participants agreed with the study giving their informed consent.

\section{Endoscopy I - Hands-on training module}

1. Small demonstration and review of basic technical aspects

2. Pre-training evaluation - "baseline EGD and colonoscopy"

3. Psychomotor exercises, up to expert level

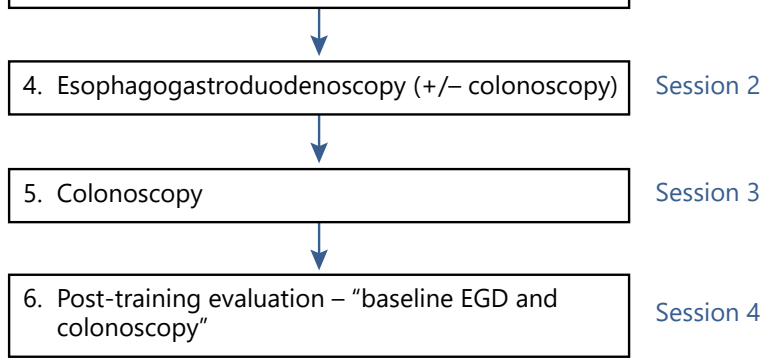

Fig. 2. Structure of the "Endoscopy I" training programme hands-on module.

\section{"Endoscopy I" General Structure}

The main objectives defined for the course were: (1) to recognize and apply the general principles of endoscopy and scope manipulation; (2) to train the basic technical skills of upper and lower endoscopy, and to practice standard/diagnostic exams.

The theoretical module included the items and duration displayed in Figure 1. The participants performed a pre-test before and a test immediately after the course. Both were equal and included 15 questions in total ( 3 per item discussed in the formation).

For the hands-on module, 10 tutors (experienced endoscopists, with also previous simulator practice) were enrolled; before the sessions they received a script with the sequence and formation aims. To facilitate the access of participants, the simulator was transported and made available in three Portuguese cities (September in Braga, October in Coimbra, and November in Lisbon).

The residents were divided into small groups (maximum 4 residents) that followed 4 hands-on sessions on VR simulator, in accordance with a defined sequence (Fig. 2). Every session lasted on average $5 \mathrm{~h}$, in which each participant trained during a period and observed his colleagues in the remaining time. The training amounted to approximately $5 \mathrm{~h}$ hands-on and $20 \mathrm{~h}$ in total for each participant, along 3-4 weeks.

In the beginning of the first hands-on session all subjects received identical pre-trial instruction on the simulator, including a demonstration by the tutor and a reminder of some basic aspects, already addressed in the previous theoretical session. Immediately after that, they all completed the trial of baseline esophagogastroduodenoscopy (EGD) (case 1, module 1) and baseline colonoscopy (case 3 , module 1 ). Then the training effectively started.

1. Psychomotor exercises (Navigation I and Endobubble I) - after a small explanation about the objectives, each exercise should be repeated up to the expert level, before the trainee moves to another task. To prevent fatigue, after 3 repetitions the resident should have a break, passing the scope to a colleague. The expert level (Table 1) and the rationale for this was defined in a previous pilot study (unpublished). 
Table 1. Definition of expert level for the psychomotor exercises (Navigation I and Endobubble I)

\begin{tabular}{|c|c|}
\hline & Expert level \\
\hline \multicolumn{2}{|l|}{ Navigation I } \\
\hline Average time to acquire a target & $5 \mathrm{~s}$ \\
\hline Total number of attempts to acquire all targets & 30 times \\
\hline \multicolumn{2}{|l|}{ Endobubble I } \\
\hline Total time & $78 \mathrm{~s}$ \\
\hline Number of wall hits & $\leq 1$ times \\
\hline
\end{tabular}

2. EGD exercises - in the second hands-on session, each participant performed, rotationally, 4 EGD cases (cases 3, 4, 5, and 8, from module 1).

3. Colonoscopy exercises - in the third hands-on session each participant performed, rotationally, 4 colonoscopy cases (cases $1,2,4$, and 9 , from module 1 ).

The training sessions, although discussing some clinical features, were mainly focused on the technical aspects, resolution of difficulties, and skills improvement. A structured constructive feedback provided by the tutor and use of feedback from the simulator (position of the scope) were available during the entire training.

4. Evaluation - the last session was used to complete the sequence, in case of any delay, and to perform the evaluation at the end - again with the baseline cases EGD (case 1, module 1) and colonoscopy (case 3, module 1) - a single pass, without any help from the tutor or scope position image. The assignment in EGD and in colonoscopy, as during hands-on training, was to reach the second part of duodenum or the cecum, respectively, as quickly as possible with minimal discomfort for the patient, and to adequately evaluate the mucosa. The individual performance metrics generated by computer were recorded under a codified number for anonymous analysis.

\section{Selected VR Exercises}

Virtual psychomotor exercises: Navigation I (fundamental skills module) - The goal of this task was to train the basic endoscope manoeuvres (tip deflections, neutral position, torque, forward/backward movements) and to gain manual dexterity in applying them properly to acquire a displayed target. Endobubble I (cyberscopy module) - This task implies the navigation through a virtual colon, combined with the task of piercing 20 balloons along the way with an injection needle; each balloon must be punctured within a certain amount of time, and collisions with the wall must be avoided.

EGD and colonoscopy training exercises: the described cases were selected as diagnostic situations with different anatomic variations, technical challenges, and diverse conditions to cover a diversity of points during the training.

Evaluation cases: upper endoscopy case 1 (module 1$)$ - diagnostic, normal endoscopy; colonoscopy case 3 (module 1) - diagnostic and normal exam, described as a complex colonoscopy, with a relatively winding sigmoid and a built-in loop in the ascending colon and hepatic flexure.
Table 2. Results of the cognitive evaluation before and after the theoretical session

\begin{tabular}{lll}
\hline Item & $\begin{array}{l}\text { Pre-test score, } \\
\text { median (IQR) }\end{array}$ & $\begin{array}{l}\text { Test score, } \\
\text { median } \\
\text { (IQR) }\end{array}$ \\
\hline Endoscopes (0-3) & $2(2-3)$ & $3(3-3)$ \\
Endoscopy accessories (0-3) & $3(3-3)$ & $2(2-3)$ \\
Endoscopes reprocessing (0-3) & $2(1.3-3)$ & $3(3-3)$ \\
Indications and Cl for endoscopy (0-3) & $2.5(2-3)$ & $3(3-3)$ \\
EGD and colonoscopy technical approach (0-3) & $2(1-2)$ & $3(2.3-3)$ \\
\hline Total score (0-15) & $11(8.3-12)$ & $14(14-15)$ \\
\hline
\end{tabular}

$\mathrm{IQR}$, interquartile range.

\section{Performance Parameters}

The cognitive pre-test and test were used to evaluate the immediate impact of the theoretical module. To evaluate the impact of the hands-on training in the skills performance, 3 metrics were selected to analyse the cases performance before and after - the time required to reach the second part of duodenum (D2) or the cecum (in the respective exam), the percentage of efficiency of screening and the percentage of time the patient was in pain/discomfort - and were considered key parameters for this study. These metrics correlate directly or indirectly with important navigation skills and quality in endoscopy.

The efficiency of screening is a composite parameter calculated by the simulator using the time of the procedure (total and time to target - duodenum or cecum) and the percentage of mucosa examined. The percentage of time the virtual patient experienced excessive pain/discomfort was calculated by the simulator combining several related parameters (pressure, air distension, loop rate).

\section{Statistical Analysis}

For comparisons of scale variables, we used non-parametric tests since the sample size is small. Wilcoxon test was used in paired samples. These variables were described using median and interquartile interval (Q1-Q3), where Q1 represents the first quartile (corresponding to $25 \%$ of data) and Q3 represents the third quartile (corresponding to $75 \%$ of data). $p$ values $<0.05$ were considered as significant. Data were analysed using SPSS software (v.22.0, SPSS, Chicago, IL, USA) and Microsoft Excel.

\section{Results}

From the 25 first-year gastroenterology residents in 2018, 23 completed the "theoretical module" evaluation, and 21 completed the "hands-on module." The participants were female in majority $(67 \%)$ and had a median average age of $26 \pm 0.7$ years. 
Table 3. Results of the endoscopic skills assessment before and after the "hands-on" VR simulator training

\begin{tabular}{|c|c|c|c|c|c|c|}
\hline \multirow[t]{2}{*}{ Parameter } & \multicolumn{3}{|c|}{ Esophagogastroduodenoscopy } & \multicolumn{3}{|l|}{ Colonoscopy } \\
\hline & $\begin{array}{l}\text { pre-training, } \\
\text { median (IQR) }\end{array}$ & $\begin{array}{l}\text { post-training, } \\
\text { median (IQR) }\end{array}$ & Wilcoxon test & $\begin{array}{l}\text { pre-training, } \\
\text { median (IQR) }\end{array}$ & $\begin{array}{l}\text { post-training, } \\
\text { median (IQR) }\end{array}$ & Wilcoxon test \\
\hline Time to D2/cecum, s & $193(99-262)$ & $63(52-89)$ & $\begin{array}{l}Z=-3.980 \\
p<0.001\end{array}$ & 599 (354-764) & $294(201-450)$ & $\begin{array}{l}Z=-3.354 \\
p=0.001\end{array}$ \\
\hline Efficiency of screening, \% & $64(41-78)$ & $91(81-95)$ & $\begin{array}{l}Z=-3.911 \\
p<0.001\end{array}$ & $50(30-72)$ & $68(49-81)$ & $\begin{array}{l}Z=-1.868 \\
p=0.062\end{array}$ \\
\hline Time the patient was in pain, $\%$ & $0(0-0)$ & $0(0-0)$ & - & $27(7-43)$ & $10(3-27)$ & $\begin{array}{l}Z=-2.839 \\
p=0.005\end{array}$ \\
\hline
\end{tabular}

$\mathrm{IQR}$, interquartile range.

\section{Theoretical Module Evaluation}

The average total score in the cognitive test completed after the theoretical training was significantly higher compared to the score in the pre-test $(Z=-4.125 ; p<$ $0.001)$. The results of the cognitive test are presented in Table 2.

\section{Endoscopic Skills Assessment}

The results of the key parameters evaluated pre- and post-training in the VR simulator are presented in Table 3.

\section{EGD}

The time required to reach D2 was significantly lower in the final assessment $(Z=-3.980 ; p<0.001)$. The percentage of efficiency of screening significantly improved in the post-training assessment $(Z=-3.911 ; p<0.001)$. The percentage of time the patient was in pain was zero in both assessments.

\section{Colonoscopy}

The time required to reach the cecum was significantly lower in the post-training assessment $(Z=-3.354 ; p=$ $0.001)$. The percentage of efficiency of screening was not statistically different $(Z=-1.868 ; p=0.062)$ yet with a tendency towards improvement (median $50 \%$ vs. $68 \%$ ). The percentage of time the patient was in pain was significantly lower in the final assessment $(Z=-2.839 ; p=0.005)$.

\section{Discussion}

The definition of the best training programme in gastrointestinal endoscopy is an international hot topic. Current evidence supports the use of VR simulation- based training for novices $[1,2,11]$, which is an educational platform whereby endoscopy training can be delivered to achieve specific and predefined learning goals. However, simply providing trainees with access to simulators does not guarantee learning $[2,16]$. There is a need for a standardized induction programme which can ensure that beginners are sufficiently armed with the basic skills and knowledge before approaching the patientbased training [10].

This study evaluates an original programme which we planned thoughtfully balanced according to information available in literature: a theoretical introduction as recommended [19], a deliberate practice involving focused repetitive performance of a skill, coupled with constructive feedback to identify weaknesses and promote selfreflection and error correction $[16,20]$, and a masterylearning model, progressing through tasks of increasing level of difficulty, with clear learning objectives associated with focused educational activities. According to experience translated from laparoscopy, the variability of the tasks included, different exercises and cases, can also improve the flexibility in the application of trained skills [16].

Moreover, innovative educational design elements stressed by Khan et al. [16] were also included. Besides the number of hours for training balanced with previous results $[18,21]$, the "spaced practice" with the distribution of training by several sessions was made in order to optimize performance $[22,23]$, as well as a "just-in-time" simulation training, as the training was provided in the immediate months before clinical practice. An additional innovative aspect was "gamification," which aligned with the learning goals and is thought to enhance learner engagement [16]. Here it was applied as psychomotor exer- 
cises (Navigation I and Endobubble I), and since we previously evaluated the construct validity, its impact on learning curves and expert level, we were able to optimize natural skills and specific needs of each resident, prolonging tasks in some and saving time in others.

Assuming competence in endoscopy as incorporating cognitive, technical, and integrative skills [24], our programme demonstrated a significant improvement between pre- and post-training performances for the first two components in novice residents.

The cognitive part was pointed out by the statistically significant evolution from pre-test to test. Although these results do not provide delayed retention, which for sure would be inferior, we believe that the discussion of the topics during hands-on training and the easy access and evocation of the contents when starting the endoscopy rotation promote effective assimilation.

Concerning the technical skills, a clear improvement was demonstrated.

In EGD, the two more important metrics (time to D2 and percentage of efficiency of screening) significantly improved. Usually, the pain is not a problem in upper endoscopy, as demonstrated in the results. Although the assessment was in a simulator, it is aligned with validated competency parameters for EGD - unassisted rate of D2 intubation, D2 intubation time, total procedure time, and Assessment of Competency in Endoscopy (ACE) skill score, which includes parameters like scope control and visualization of mucosa [25].

On the other side, for colonoscopy, the percentage of time the patient was in pain and time to reach the cecum were significantly lower in the final assessment. The percentage of efficiency of screening was not statistically different; however, with a tendency towards improvement. In fact, the residents at this stage spent more time inspecting the mucosa and therefore deteriorated this metric, which includes in calculation the total procedure time. Again, the metrics evaluated are aligned with validated competency parameters for colonoscopy - unassisted cecal intubation rate, intubation time, and ACE skill score, which includes parameters like scope control/navigation and visualization of mucosa [26].

Globally it seems that residents developed their technical skills of navigation and manoeuvring the scope, allowing the achievement of higher performances in metrics dependent on dexterity and subsequently time measure. This study did not assess the translation of the VR improvement into patient-based endoscopy. However, this has already been demonstrated in randomized controlled trials in novices with GI Mentor II. For instance, Ferlitsch et al. [27] showed that virtual simulator training significantly helps to reduce the time needed to reach upper endoscopy technical competency in patients. And Koch et al. [9] demonstrated that it leads to a significant improvement in performance with the simulator itself and, during patient-based colonoscopy.

Returning to competence determinants, the integrative skills are essential to execute quality endoscopy in different scenarios [24]. Although it was not evaluated in this study, as the focus at this stage of training is the technique, the non-technical skills were introduced during small group interactive discussion when on hands-on sessions.

Several limitations can be pointed to our study. The sample size is small (considering it was a convenience sample), with no formal power calculation, although similar to most other studies on this topic. Various tutors were included, and besides experience and specific instructions and orientation they had no formal training as recommended for trainers [28]. The exercises tested, and the metrics used represent only a selection between multiple possibilities given by the simulator. The study was unblinded, although all the evaluation parameters were objectively generated by the GI Mentor software. As previously said, we were not able to evaluate the translation to patient-based or skills retention, although other studies demonstrated that skills acquired after VR colonoscopy seem to be maintained for several months after the end of training [29].

To our knowledge this is the first study reporting the outcomes of a real-life, thoughtfully structured programme for VR endoscopic training in novices (null endoscopic experience) that includes theoretical and handson practice in both upper endoscopy and colonoscopy. However, these activities should be grounded in evidence to maximize its learning benefits and outweigh associated costs, which is the main rationale for this evaluation and reflection. The described programme is currently applied to endoscopy novices every year, included in a 5-year curriculum of training in GI endoscopy for gastroenterology residents promoted by SPED.

In conclusion, the proposed training curriculum in basic endoscopy for novices is aligned with international recommendations and demonstrated a significant impact on cognitive and technical skills learning achievements. The time to reach the duodenum or the cecum and the percentage of time the patient was in pain clearly improved with the VR training, which attests increased dexterity in using and controlling the endoscope. 


\section{Acknowledgement}

The authors would like to acknowledge all the faculty/tutors enrolled in the "Endoscopy I, 2018" programme - Bruno Rosa, Filipe Vilas Boas, Lídia Ramos, Liliana Eliseu, Luís Elvas, Nuno Veloso, Pedro Amaro, Ricardo Cardoso, Rosa Ferreira, Rui Loureiro, Sandra Barbeiro and Susana Mão-de-Ferro - for their crucial role in different steps. Finally, we would also like to thank the participants, the secretariat, and all the members of the Education Committee of SPED.

\section{Statement of Ethics}

This study protocol was reviewed and approved by the University of Minho (UM) Ethics Subcommission of Life and Health Sciences, and the subjects participating in this study gave their written informed consent.

\section{Conflict of Interest Statement}

Sofia Silva Mendes and Carla Rolanda have no conflicts of interest (COI) or financial ties to disclose. Miguel Areia has no COI or financial ties to disclose related with the present work.
He was the president of SPED between 2019 and 2021. Mário Dinis Ribeiro has no COI or financial ties to disclose related with the present work. He was president of SPED between 2017 and 2019.

\section{Funding Sources}

This work had no grant support or other specific sources of funds.

\section{Author Contributions}

Sofia Silva Mendes: collection and/or assembly of data, data analysis and interpretation, manuscript writing; Miguel Areia and Mário Dinis Ribeiro contributed to critical revision of the manuscript for important intellectual content and final approval of this article; Carla Rolanda: conception and design, data analysis and interpretation, manuscript writing.

\section{References}

1 Waschke KA, Coyle W. Advances and Challenges in Endoscopic Training. Gastroenterology. 2018 May;154(7):1985-92.

2 Siau K, Hawkes ND, Dunckley P. Training in Endoscopy. Curr Treat Options Gastroenterol. 2018 Sep;16(3):345-61.

3 Goodman AJ, Melson J, Aslanian HR, Bhutani MS, Krishnan K, Lichtenstein DR, et al.; ASGE Technology Committee. Endoscopic simulators. Gastrointest Endosc. 2019 Jul;90(1):1-12.

4 Triantafyllou K, Lazaridis LD, Dimitriadis GD. Virtual reality simulators for gastrointestinal endoscopy training. World J Gastrointest Endosc. 2014 Jan;6(1):6-12.

5 Buzink SN, Koch AD, Heemskerk J, Botden SM, Goossens RH, de Ridder H, et al. Acquiring basic endoscopy skills by training on the GI Mentor II. Surg Endosc. 2007 Nov;21(11):1996-2003.

6 Koch AD, Buzink SN, Heemskerk J, Botden SM, Veenendaal R, Jakimowicz JJ, et al. Expert and construct validity of the Simbionix GI Mentor II endoscopy simulator for colonoscopy. Surg Endosc. 2008 Jan;22(1):15862.

7 Sedlack RE, Kolars JC, Alexander JA. Computer simulation training enhances patient comfort during endoscopy. Clin Gastroenterol Hepatol. 2004 Apr;2(4):348-52.

8 Park J, MacRae H, Musselman LJ, Rossos P, Hamstra SJ, Wolman S, et al. Randomized controlled trial of virtual reality simulator training: transfer to live patients. Am J Surg. 2007 Aug;194(2):205-11.

9 Koch AD, Ekkelenkamp VE, Haringsma J, Schoon EJ, de Man RA, Kuipers EJ. Simulated colonoscopy training leads to improved performance during patient-based assessment. Gastrointest Endosc. 2015 Mar;81(3):630-6.

10 Siau K, Hodson J, Neville P, Turner J, Beale A, Green S, et al. Impact of a simulation-based induction programme in gastroscopy on trainee outcomes and learning curves. World J Gastrointest Endosc. 2020 Mar;12(3):98110.

11 Ekkelenkamp VE, Koch AD, de Man RA, Kuipers EJ. Training and competence assessment in GI endoscopy: a systematic review. Gut. 2016 Apr;65(4):607-15.

12 Khan R, Plahouras J, Johnston BC. Virtual reality simulation training for health professions trainees in gastrointestinal endoscopy. Cochrane Database Syst Rev. 2018; 17;8:CD008237.

13 Jirapinyo $\mathrm{P}$, Abidi WM, Aihara $\mathrm{H}$, Zaki T, Tsay C, Imaeda AB, et al. Preclinical endoscopic training using a part-task simulator: learning curve assessment and determination of threshold score for advancement to clinical endoscopy. Surg Endosc. 2017 Oct:31(10):4010-5.

14 Rolanda C, Vilas-Boas F, Eliseu L. SPED Statement: Training in Gastrointestinal Endoscopy. Endoscopy. 2019;51(10):1003-4.
15 Rolanda C, Sadio A, Loureiro R. SPED Statement: Training in Gastrointestinal Endoscopy. Endoscopy. 2019;51(11):1103-4.

16 Khan R, Scaffidi MA, Grover SC, Gimpaya N, Walsh CM. Simulation in endoscopy: practical educational strategies to improve learning. World J Gastrointest Endosc. 2019 Mar;11(3):209-18.

17 Grover SC, Garg A, Scaffidi MA, Yu JJ, Plener IS, Yong E, et al. Impact of a simulation training curriculum on technical and nontechnical skills in colonoscopy: a randomized trial. Gastrointest Endosc. 2015 Dec;82(6):1072-9.

18 Grover SC, Scaffidi MA, Khan R, Garg A, AlMazroui A, Alomani T, et al. Progressive learning in endoscopy simulation training improves clinical performance: a blinded randomized trial. Gastrointest Endosc. 2017 Nov;86(5):881-9.

19 Götzberger M, Rösch T, Geisenhof S, Gülberg V, Schmitt W, Niemann G, et al. Effectiveness of a novel endoscopy training concept. Endoscopy. 2011 Sep;43(9):802-7.

20 Kruglikova I, Grantcharov TP, Drewes AM, Funch-Jensen P. The impact of constructive feedback on training in gastrointestinal endoscopy using high-fidelity Virtual-Reality simulation: a randomised controlled trial. Gut. 2010 Feb;59(2):181-5.

21 Harpham-Lockyer L, Laskaratos FM, Berlingieri P, Epstein O. Role of virtual reality simulation in endoscopy training. World J Gastrointest Endosc. 2015 Dec;7(18):1287-94. 
22 Walker MP, Stickgold R, Alsop D, Gaab N, Schlaug G. Sleep-dependent motor memory plasticity in the human brain. Neuroscience. 2005;133(4):911-7.

23 Verdaasdonk EG, Stassen LP, van Wijk RP, Dankelman J. The influence of different training schedules on the learning of psychomotor skills for endoscopic surgery. Surg Endosc. 2007 Feb;21(2):214-9.

24 Dubé C, Rostom A. Acquiring and maintaining competency in gastrointestinal endoscopy. Best Pract Res Clin Gastroenterol. 2016 Jun;30(3):339-47.
25 Miller AT, Sedlack RE, Sedlack RE, Coyle WJ, Obstein KL, Poles MA, et al.; ACE Research Group. Competency in esophagogastroduodenoscopy: a validated tool for assessment and generalizable benchmarks for gastroenterology fellows. Gastrointest Endosc. 2019 Oct;90(4):613-620.e1.

26 Sedlack RE, Coyle WJ, Sedlack RE, Coyle WJ, Obstein KL, Poles MA, et al.; ACE Research Group. Assessment of competency in endoscopy: establishing and validating generalizable competency benchmarks for colonoscopy. Gastrointest Endosc. 2016 Mar;83(3):516-23.e1.
27 Ferlitsch A, Schoefl R, Puespoek A, Miehsler W, Schoeniger-Hekele M, Hofer H, et al. Effect of virtual endoscopy simulator training on performance of upper gastrointestinal endoscopy in patients: a randomized controlled trial. Endoscopy. 2010 Dec;42(12):1049-56.

28 Waschke KA, Anderson J, Valori RM, MacIntosh DG, Kolars JC, DiSario JA, et al.; Chair of 2017-18 ASGE Training Committee. ASGE principles of endoscopic training. Gastrointest Endosc. 2019 Jul;90(1):27-34.

29 Snyder CW, Vandromme MJ, Tyra SL, Hawn MT. Retention of colonoscopy skills after virtual reality simulator training by independent and proctored methods. Am Surg. 2010 Jul;76(7):743-6. 